\title{
High Prion and $\operatorname{PrP}^{\mathrm{Sc}}$ Levels but Delayed Onset of Disease in Scrapie-Inoculated Mice Heterozygous for a Disrupted PrP Gene
}

\author{
Hansruedi Büeler, * Alex Raeber, Andreas Sailer, ${ }^{\dagger}$ Marek \\ Fischer, Adriano Aguzzi, ${ }^{\neq}$and Charles Weissmann \\ Institut für Molekularbiologie I, Universität Zürich, Hönggerberg, \\ Zürich, Switzerland \\ ${ }^{\ddagger}$ Institut für Neuropathologie, Universitätsspital Zürich, \\ Zürich, Switzerland
}

\begin{abstract}
Background: It has been proposed that the prion, the infectious agent of transmissible spongiform encephalopathies, is $\operatorname{PrP}^{\mathrm{Sc}}$, a post-translationally modified form of the normal host protein $\operatorname{PrP}^{\mathrm{C}}$. We showed previously that mice devoid of $\operatorname{PrP}^{\mathrm{C}}\left(\mathrm{Prn}-\mathrm{p}^{0 / 0}\right)$ are completely resistant to scrapie. We now report on the unexpected response of heterozygous $\left(\mathrm{Prn}-\mathrm{p}^{\mathrm{O/+}}\right)$ mice to scrapie infection.

Materials and Methods: Prn- $p^{0 /+}, P r n-p^{0 / 0}$ and Prn$p^{+/+}$mice were obtained from crosses of Prn-p $p^{o /+}$ mice. Mice were inoculated intracerebrally with mouse-adapted scrapie agent and the clinical progression of the disease recorded. Mice were sacrificed at intervals, $\operatorname{PrP}^{\mathrm{Sc}}$ was determined as protease-resistant PrP and the prion titer by the incubation time assay. Results: $P r n-p^{o /+}$ mice, which have about half the normal level of $\mathrm{PrP}^{\mathrm{C}}$ in their brains, show enhanced
\end{abstract}

resistance to scrapie, as manifested by a significant delay in onset and progression of clinical disease. However, while in wild type animals an increase in prion titer and $\operatorname{PrP}^{\mathrm{Sc}}$ levels is followed within weeks by scrapie symptoms and death, heterozygous Prn- $p^{o /+}$ mice remain free of symptoms for many months despite similar levels of scrapie infectivity and $\operatorname{Pr} \mathrm{P}^{\mathrm{Sc}}$.

Conclusions: Our findings extend previous reports showing an inverse relationship between PrP expression level and incubation time for scrapie. However, contrary to expectation, overall accumulation of $\mathrm{PrP}^{\mathrm{Sc}}$ and prions to a high level do not necessarily lead to clinical disease. These findings raise the question whether high titers of prion infectivity could also persist for long periods under natural circumstances in the absence of clinical symptoms.

\section{INTRODUCTION}

The transmissible agent causing spongiform encephalopathies, such as scrapie or bovine spongiform encephalopathy in animals or Creutz-

Address correspondence and reprint requests to: Charles Weissmann, Institut für Molekularbiologie I, Universität Zürich, Hönggerberg, 8093 Zürich, Switzerland.

*Present address: Whitehead Institute for Biomedical Research, Nine Cambridge Center, Cambridge, MA 02142, U.S.A.

†Present address: Molecular Neurobiology Laboratory, Salk Institute, 10010 North Torrey Pines Road, La Jolla, CA 92037, U.S.A.
feldt-Jakob disease in man, the prion (1), appears to be devoid of nucleic acid and identical to $\operatorname{PrP}^{\mathrm{Sc}}$, a modified form of $\operatorname{PrP}^{\mathrm{C}}$ (the "protein only" hypothesis) (2-5). $\operatorname{PrP}^{\mathrm{C}}$ is a normal host protein $(6,7)$ encoded within a single exon of a single copy gene (8) and is found predominantly on the surface of neurons, attached by a glycoinositol phospholipid anchor $(9,10)$. The PrP gene is also expressed in a variety of other tissues, both in the embryonic and the adult animal $(11,12)$.

$\mathrm{PrP}^{\mathrm{Sc}}$ is defined as a protease-resistant form of $\mathrm{PrP}^{\mathrm{C}}$, which readily aggregates after treatment 
with detergents $(6,13,14)$. It accumulates intracellularly in cytoplasmic vesicles (14-16) and is the major component of the extracellular amyloid plaques characteristic for prion diseases. No chemical differences have so far been detected between $\operatorname{PrP}^{\mathrm{Sc}}$ and $\operatorname{PrP}^{\mathrm{C}}(17,18)$.

It has been proposed that $\operatorname{PrP}^{\mathrm{Sc}}$, when introduced into a normal cell, causes the conversion of $\operatorname{PrP}^{\mathrm{C}}$ or its precursor to $\operatorname{PrP}^{\mathrm{Sc}}(3,6,19-21)$. The conversion has been ascribed to a post-translational conformational modification resulting in a substantial increase in $\beta$-pleated sheet structure (22). The existence of many different strains of scrapie that can be propagated in one and the same inbred mouse line and the apparent mutability of the agent $(23,24)$ still await a satisfactory explanation (25).

The essential role of PrP for scrapie disease and prion propagation is supported by a series of seminal transgenetic experiments by Prusiner and his colleagues (for reviews, see 4,20,26) and by the demonstration in our laboratory $(27,28)$ that mice devoid of functional PrP genes are resistant to scrapie and do not propagate prions, an observation subsequently confirmed by others (29); Manson et al. (personal communication). It was also noted that mice heterozygous for the disrupted PrP gene (Prn-p $p^{0 /+}$ mice) showed a very much longer incubation time for scrapie than congenic wild-type animals $(28,29)$. In this paper we report the unexpected finding that while in wild-type animals an increase in prion titer and $\mathrm{PrP}^{\mathrm{Sc}}$ is followed within a few weeks by scrapie symptoms and death, heterozygous Prn- $p^{0 /+}$ mice have levels of scrapie infectivity and $\operatorname{PrP}^{\mathrm{Sc}}$ comparable to their terminally ill wild-type counterparts for many months prior to clinical disease and death.

\section{MATERIALS AND METHODS}

\section{Animals}

Prn- $p^{+/+}$mice were obtained from Prn- $p^{0 /+}$ breeding pairs and identified by the polymerase chain reaction as described (32). A second set of $P r n-p^{0 /+}$ mice were obtained by crossing Prn- $p^{+/+}$ with Prn- $p^{0 / 0}$ mice. Prn- $p^{0 /+} / \mathrm{SHaPrP}^{0 /+}, \mathrm{Prn}^{-p^{0 / 0} /}$ SHaPrP $P^{0 /+}$, Prn- $p^{0 / O}$, and Prn- $p^{0 /+}$ mice were obtained from crosses between Prn- $\mathrm{p}^{0 / 0}$ and Prn- $p^{0 /+} / \mathrm{SHaPrP}^{\mathrm{O/+}}$ mice.

\section{Inoculations and Scrapie Diagnosis}

RML (35) is a mouse-adapted prion isolate. Sc237 is a Syrian hamster-adapted prion (13). Mice were inoculated intracerebrally with $30 \mu \mathrm{l}$ of $1 \%(\mathrm{w} / \mathrm{v})$ brain homogenate of either RML or Sc237 isolate using a 26-gauge hypodermic needle which was inserted into the right parietal lobe. Mice were monitored for decreased motor activity and ataxia as early symptoms, and mincing gait, "plastic tail," disorientation, feet clasping when lifted, and depression as later symptoms.

\section{Preparation of Brain Homogenates and Titration of Infectivity}

Ten percent $(\mathrm{w} / \mathrm{v})$ brain homogenates in $0.32 \mathrm{M}$ sucrose were prepared by slowly passing the brains back and forth first through an 18-gauge and then a 22-gauge needle. Once the solution appeared homogeneous, it was spun for $10 \mathrm{~min}$ at $500 \times \mathrm{g}$ and the supernatant was diluted 10 -fold in PBS-5\% BSA to yield the inoculum. For the endpoint titration of the 50-week sample, 10 -fold serial dilutions up to $10^{-8}$ were prepared in PBS-5\% BSA. Of each dilution, $30 \mu \mathrm{l}$ were injected intracerebrally into six Swiss CD-1 mice, and the animals were monitored for scrapie symptoms as described above.

\section{Histology}

Mouse brains were fixed in PBS containing $4 \%$ formaldehyde for at least $24 \mathrm{hr}$, incubated for 60 min in concentrated formic acid (36), and washed with PBS. Coronal slices of approximately $2 \mathrm{~mm}$ were dehydrated through graded alcohols and embedded in paraffin. Sections of 3 $\mu \mathrm{m}$ nominal thickness were stained with hematoxylin and eosin. Immunostains for glial fibrillary acidic protein (GFAP) were performed using a rabbit anti-GFAP antiserum (DAKO, Copenhagen, Denmark) at a dilution of 1:300. The secondary antibody was a biotinylated swine-antirabbit IgG serum at a working dilution of 1:250. Visualization was achieved using avidin-peroxidase (DAKO) and diaminobenzidine (Sigma). Slices were mounted in Entellan (Merck).

\section{Western Blot Analysis of PrP in Brain Homogenates}

Brain homogenates $(10 \% \mathrm{w} / \mathrm{v})$ were adjusted to $8 \mathrm{mg} / \mathrm{ml}$ of protein (BCA assay according to 
TABLE 1. Incubation times to onset of disease and death

\begin{tabular}{|c|c|c|}
\hline \multirow[b]{2}{*}{ Genotype of Host } & \multicolumn{2}{|c|}{ Prion Inoculum } \\
\hline & Mouse (RML) & Hamster (Sc237) \\
\hline \multicolumn{3}{|l|}{ Prn- $\boldsymbol{p}^{+/+a}$} \\
\hline Disease & $158 \pm 11$ & ND $(>600)$ \\
\hline Death & $171 \pm 11$ & --- \\
\hline \multicolumn{3}{|l|}{$\operatorname{Prn}-p^{o /+}$} \\
\hline Disease & $290 \pm 33(n=19)$ & $>600(n=9)$ \\
\hline Death & $415 \pm 30(n=15)$ & --- \\
\hline \multicolumn{3}{|l|}{ Prn-p $p^{o /+} / S H a P r P^{0 /+}$} \\
\hline Disease & $260 \pm 22(\mathrm{n}=15)^{b}$ & $67 \pm 4(n=9)$ \\
\hline Death & $280 \pm 23(n=12)$ & $72 \pm 7(n=6)$ \\
\hline \multicolumn{3}{|l|}{$\operatorname{Prn}-p^{o / o} / S H a P r P^{0 /+}$} \\
\hline Disease & $323 \pm 60(\mathrm{n}=18)$ & $58 \pm 2(\mathrm{n}=6)^{c}$ \\
\hline Death & $341 \pm 60(\mathrm{n}=16)$ & $60 \pm 5(n=9)$ \\
\hline \multicolumn{3}{|l|}{$\operatorname{Prn}-p^{o / o}$} \\
\hline Disease & $>600(n=10)$ & $>600(n=5)$ \\
\hline Death & --- & --- \\
\hline
\end{tabular}

Pierce, Rockford, IL, U.S.A.) in $0.32 \mathrm{M}$ sucrose, $0.5 \%$ NP40, and $0.5 \%$ deoxycholate. Samples (80-200 $\mu \mathrm{g}$ of protein) were electrophoresed through a $1.5 \mathrm{~mm} 12.5 \%$ SDS-polyacrylamide gel (acrylamide:bisacrylamide, 29:1) (37). Proteins were transferred to nitrocellulose (Schleicher and Schüll; BA 85, 0.45-mm pore size) by semi-dry electroblotting (IKA Biotech, Denmark). The membrane was blocked by incubating for $1 \mathrm{hr}$ in TBST $(0.01 \mathrm{M}$ Tris- $\mathrm{HCl}, \mathrm{pH} 8.0$, $0.15 \mathrm{M} \mathrm{NaCl}, 0.1 \%$ Tween 20 ) containing $5 \%$ non-fat dry milk and incubated overnight at $4^{\circ} \mathrm{C}$ in TBST, 1\% non-fat dry milk, and anti-PrP27-30 antiserum R073 (diluted 1:5,000) (38). After washing four times for $5 \mathrm{~min}$ in TBST, the membrane was incubated for $1 \mathrm{hr}$ in TBST, $1 \%$ nonfat dry milk, and peroxidase-labeled anti-rabbit antiserum (Amersham; diluted 1:2,500), washed once for $10 \mathrm{~min}$ and three times for $5 \mathrm{~min}$ in TBST, developed using the enhanced chemiluminescence detection (ECL) kit from Amersham, and exposed to Kodak X-ray film. Chemoluminescence of the bands was quantified by scan- ning an appropriate film exposure with a laser densitometer (Molecular Dynamics, CA, U.S.A.).

\section{RESULTS}

Challenge of Prn- $p^{+/+}$and Prn- $p^{0 /+}$ Mice
with Mouse and Hamster Prions

Prn- $p^{+/+}$mice inoculated intracerebrally with a high dose $\left(10^{7} \mathrm{LD}_{50} \mathrm{U}\right)$ of the Chandler-derived isolate of mouse-adapted prions (RML) developed neurological symptoms at $158 \pm 11$ days and died at $171 \pm 11$ days, respectively (Table 1 and Fig. 1A). Unexpectedly, similarly inoculated Prn- $p^{O /+}$ mice, which express about half as much $\operatorname{PrP}^{\mathrm{C}}$ as Prn- $p^{+/+}$mice (see below), developed neurological disease only after $290 \pm 33$ days (Table 1). Moreover, not only the onset of the disease but also the progression of the clinical phase was drastically retarded in Prn- $p^{0 /+}$ mice as compared with Prn- $\mathrm{p}^{+/+}$mice (Fig. lA). Thus, the average interval between onset of neurolog- 
A

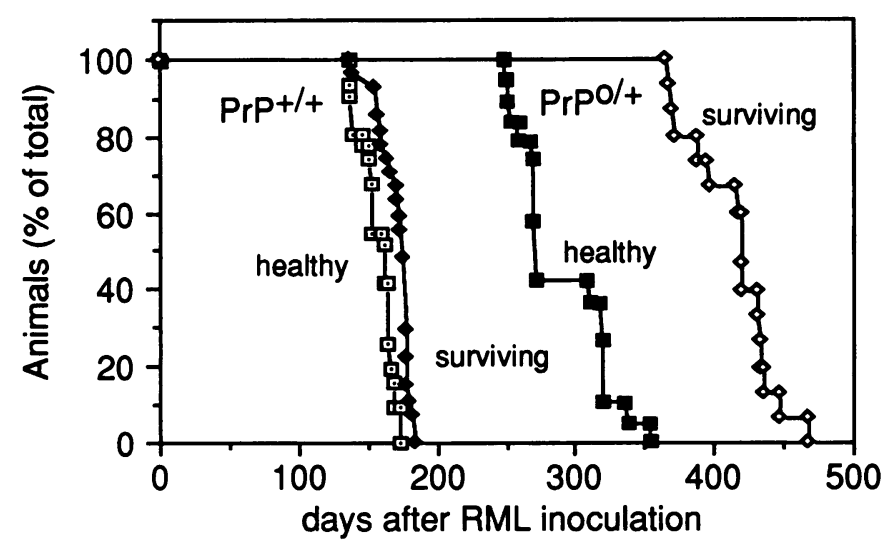

B

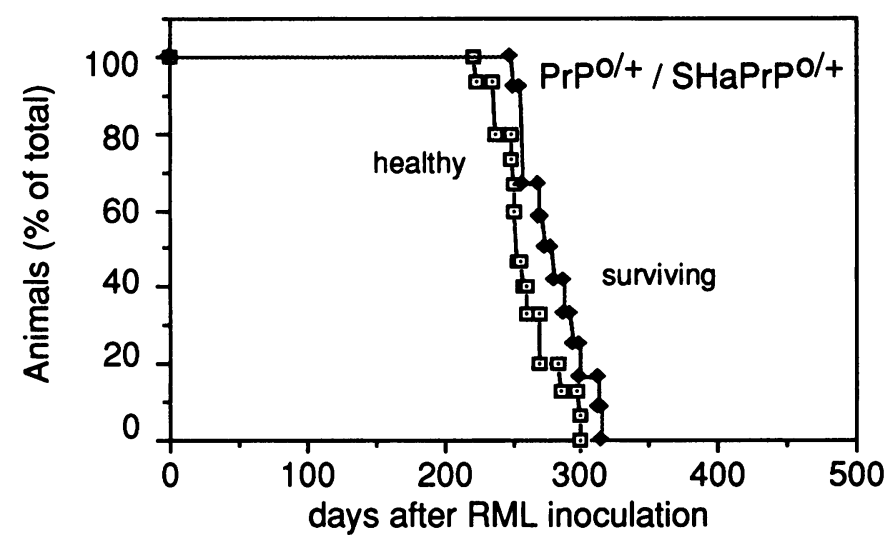

C

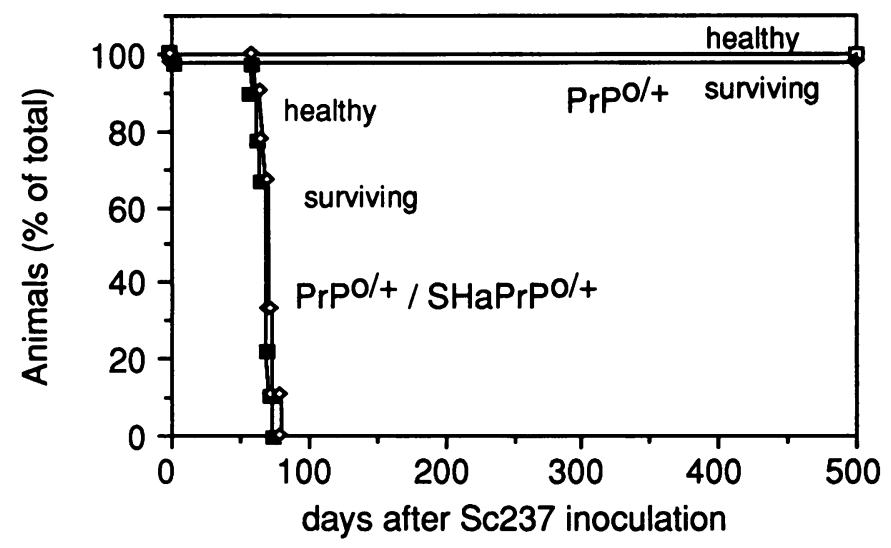

FIG. 1. Symptom-free and surviving Prn- $p^{+/+}, P r n-p^{0 /+}$, and Prn- p $^{o /+} /$ SHaPrP $^{0 /+}$ mice after inoculation with mouse or hamster prions

Inoculations were as described in Experimental Procedures. (A) Thirty-one $\mathrm{Prn}-\mathrm{p}^{+/+}$and $19 \mathrm{Prn}-\mathrm{p}^{0 /+}$ mice after inoculation with mouse RML prions. (B) Fifteen Prn-po/+ / SHaPrP $\mathrm{P}^{\mathrm{O}+}$ mice after inoculation with mouse RML prions. (C) Eight Prn- $p^{0 /+}$ and 9 Prn- $p^{0 /+} /$ SHaPrP $P^{0 /+}$ mice after inoculation with hamster Sc237 prions.

ical symptoms and death after inoculation with RML prions was only 13 days for Prn- p $^{+/+}$mice but about 125 days for Prn- $p^{0 /+}$ mice (Table 1). Inoculation of Prn- $p^{0 /+}$ mice with hamster Sc237 prions did not lead to disease by 600 days (Table 1 and Fig. 1C), as expected from the species barrier for prion transmission between hamster and mice $(3,13)$.

Prn- $p^{0 /+}$ mice into which multiple Syrian hamster PrP transgenes had been introduced by mating $\left(\mathrm{Prn}-\mathrm{p}^{0 /+} / \mathrm{SHaPrn}-\mathrm{p}^{0 /+}\right)$ were inoculated with mouse (RML) or hamster (Sc237) prions.
The mice inoculated with mouse prions developed scrapie symptoms $260 \pm 22$ days and died $280 \pm 23$ days after inoculation (Table 1 and Fig. 1B), while the animals challenged with hamster prions fell ill after $67 \pm 4$ days and died after $72 \pm 7$ days, respectively (Table 1 and Fig. 1C). The short incubation time of $\mathrm{Prn}_{-\mathrm{p}}{ }^{/ /+}$, SHaPrn- ${ }^{0 /+}$ mice after inoculation with hamster prions is in line with the results obtained in mice possessing the same high complement of Syrian hamster PrP genes on a wild-type murine Prn$p^{+/+}$(30) or Prn- $p^{0 / 0}(28)$ background, but the 

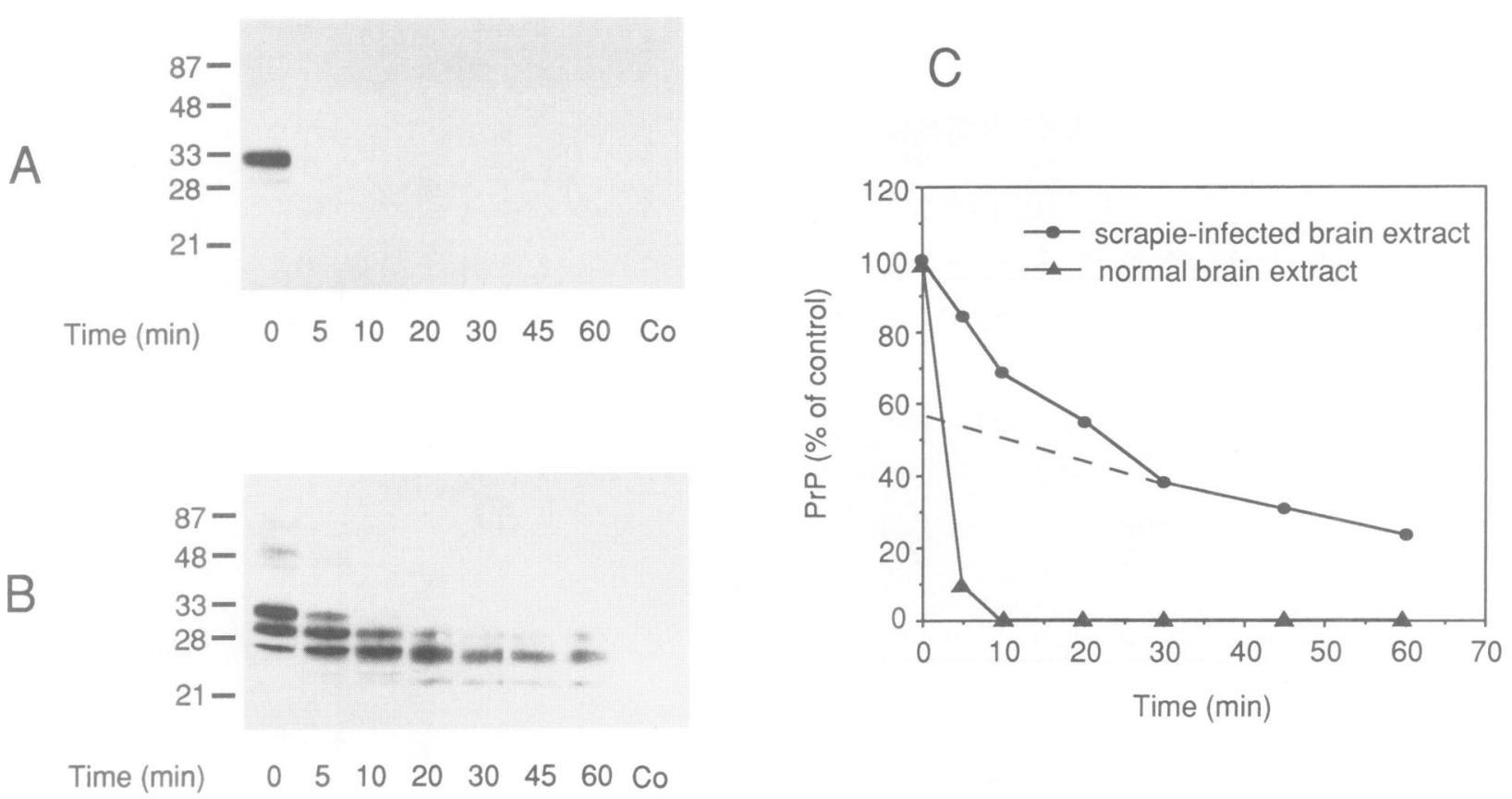

FIG. 2. Time course of protease digestion of PrP in brain extracts of uninfected and prion-inoculated wild-type mice

Brain extracts were prepared, digested with proteinase $\mathrm{K}$ for the times indicated, and PrP-specific protein was determined by Western analysis, all as described in the Experimental Procedures. (A) Normal brain. Each lane was loaded with $120 \mu \mathrm{g}$ of total protein. (B) Scrapie-infected brain (20 weeks p.i. with mouse-adapted prions). Each lane was loaded with $120 \mu \mathrm{g}$ of total protein. (C) Chemoluminescence of the bands on the Western blots (A) and (B) was quantified by scanning an appropriate film exposure. Values are expressed relative to the undigested control. Co, Prn-poro control.

finding that infection with mouse prions also showed a shorter incubation time in $P r n-p^{0 /+} /$ SHaPrn- $p^{0 /+}$ than in Prn- $p^{0 /+}$ mice was unexpected and suggests that the mouse prions converted not only the homologous mouse $\operatorname{PrP}^{\mathrm{C}}$ but also the hamster $\operatorname{PrP}^{\mathrm{C}}$ to $\mathrm{PrP}^{\mathrm{Sc}}$. This supposition needs to be confirmed by analysis of the species specificity of prions resulting from this experiment.

\section{$\operatorname{PrP}^{\mathrm{C}}$ and $\operatorname{PrP}^{\mathrm{SC}}$ in Brains of Prn- $\boldsymbol{p}^{+/+}$and Prn-p ${ }^{\text {o/+ }}$ Mice}

We first optimized the conditions for determining $\mathrm{PrP}^{\mathrm{Sc}}$, which is operationally defined as protease-resistant PrP (6). Brain homogenates from uninfected and scrapie-infected wild-type mice were treated with varying amounts of proteinase $\mathrm{K}$ for increasing lengths of times and the digests were subjected to Western analysis using the polyclonal antiserum R073 (data not shown). A proteinase $\mathrm{K}$ concentration was chosen that allowed comparison of the degradation rates of PrP from normal and scrapie-infected brain (Fig. 2). At $20 \mu \mathrm{g}$ proteinase $\mathrm{K} / \mathrm{ml}$, PrP in uninfected brain homogenates $\left(\mathrm{PrP}^{\mathrm{C}}\right)$ was $90 \%$ degraded after $5 \mathrm{~min}$ and $>95 \%$ degraded after $10 \mathrm{~min}$. In infected brain homogenates PrP was degraded with what appeared to be biphasic kinetics (Fig. 2C). After a relatively rapid decrease within the first $10 \mathrm{~min}$, at a rate of about $3 \%$ of initial $\mathrm{PrP} / \mathrm{min}$, the residual PrP decreased at a rate of about $0.7 \%$ of initial $\mathrm{PrP} / \mathrm{min}$. This slowly degraded fraction, which is not present in uninfected brain, is operationally defined as $\mathrm{PrP}^{\mathrm{Sc}}$. However, it is striking that even in the first phase of degradation the rate is 5-10 times slower in infected than in uninfected brain homogenates, suggesting that PrP may occur in a state of protease resistance intermediate between $\operatorname{PrP}^{\mathrm{C}}$ and $\mathrm{PrP}^{\mathrm{Sc}}$. We chose a $30 \mathrm{~min}$ incubation at $20 \mu \mathrm{g}$ of proteinase $\mathrm{K} / \mathrm{ml}$ as the standard assay for $\mathrm{PrP}^{\mathrm{Sc}}$; under these conditions extrapolation of the second phase of degradation to time 0 indicates that about $40 \%$ of $\operatorname{PrP}^{\mathrm{Sc}}$ had been lost.

Figure 3 shows the Western blots and the 

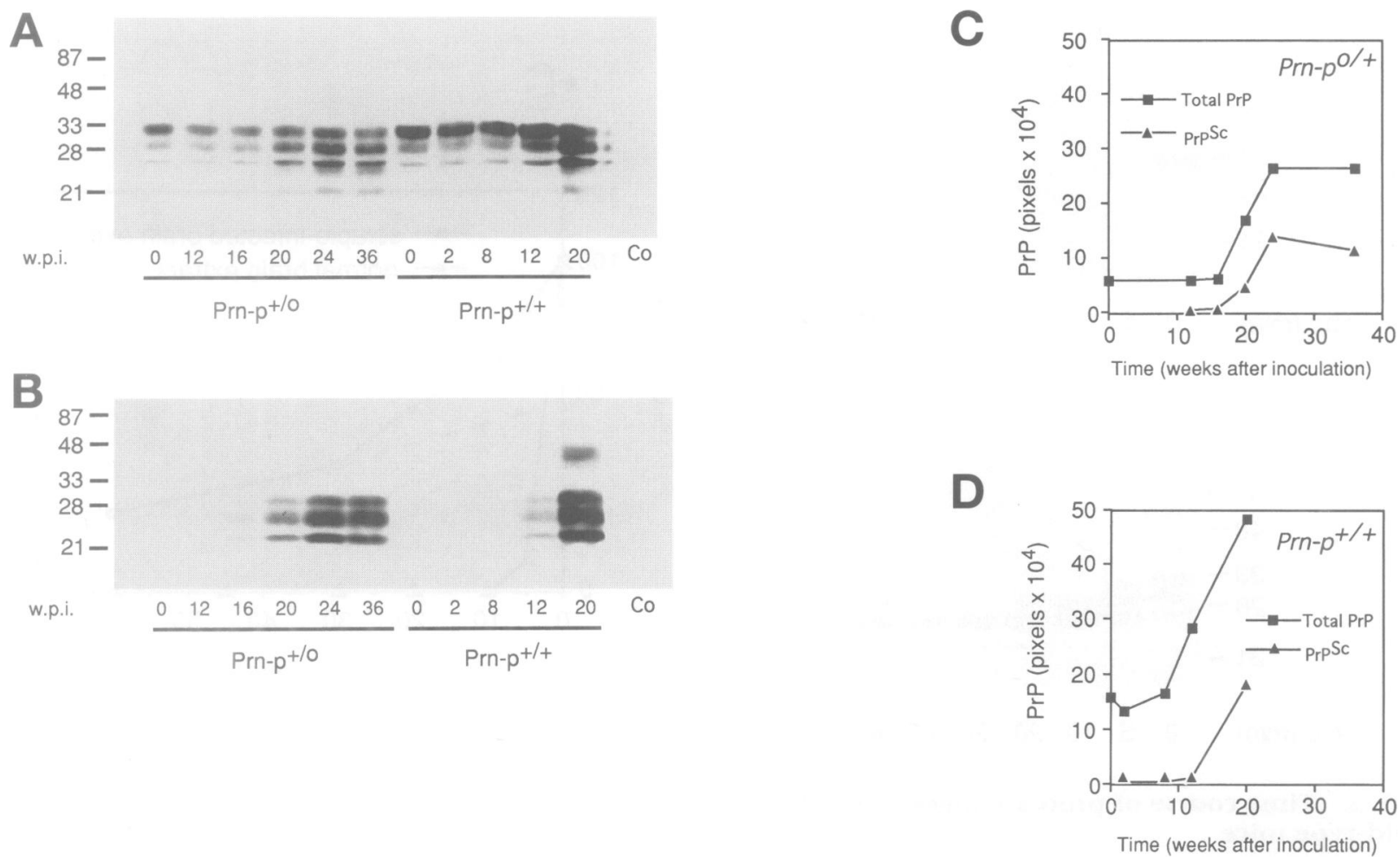

FIG. 3. Total and protease-resistant PrP in brain homogenates of Prn-p ${ }^{+/+}$and Prn- $p^{o /+}$ mice at various times after inoculation with mouse prions

Mice were inoculated with mouse-adapted prions and sacrificed after the times indicated. Brain extracts were prepared, digested with proteinase $\mathrm{K}$ (total protein $8 \mathrm{mg} / \mathrm{ml}$; proteinase $\mathrm{K}, 20 \mu \mathrm{g} / \mathrm{ml}, 30 \mathrm{~min}$ at $37^{\circ} \mathrm{C}$ ), and PrPspecific protein was determined by Western analysis, all as described in Experimental Procedures (A). Total PrP, $80 \mu \mathrm{g}$ protein per lane (B). Protease-resistant PrP, $200 \mu \mathrm{g}$ protein per lane. Quantification of total PrP and protease-resistant PrP in (C) Prn- $p^{o /+}$ and (D) Prn- $p^{+/+}$mice, expressed in arbitrary units ("pixels" per lane for all bands). Co, Prn- $p^{O / O}$ control; w.p.i, weeks post inoculation.

quantification of total PrP and protease-resistant $\operatorname{PrP}\left(\mathrm{PrP}^{\mathrm{Sc}}\right)$ at different times after inoculation with mouse prions, in Prn- $p^{+/+}$and Prn-p ${ }^{0 /+}$ mice. The level of total PrP in Prn- $p^{0 /+}$ mice prior to inoculation was about half that in wild-type animals (Fig. 3A), and no protease-resistant material was detectable in either case $(<0.1 \%$ of total PrP) (Fig. 3B). After inoculation, the total level of $\operatorname{PrP}$ in wild-type animals remained constant for about 8 weeks and then increased to 3-4 times the normal level; in Prn- $p^{0 /+}$ mice the level remained constant for about 16 weeks and then rose to 4-5 times the normal Prn- $p^{0 /+}$ level (Fig. 3A). In wild-type animals, $\operatorname{PrP}^{\mathrm{Sc}}$ became detectable $\left(0.5 \%\right.$ of total $\mathrm{PrP} ; 10^{2.8}$ arbitrary units) 8 weeks after inoculation and increased to a maximum of $37 \%\left(10^{5.2}\right.$ arbitrary units $)$ of total PrP by week 20, 4 weeks before death. In heterozygotes, $\mathrm{PrP}^{\mathrm{Sc}}$ was measurable $(0.7 \%$ of total PrP; $10^{2.6}$ arbitrary units) 12 weeks after inoculation and reached a maximum of $52 \%$ of total PrP ( $10^{5.1}$ arbitrary units) after 24 weeks, a value at which it persisted for about 36 weeks. The maximum $\mathrm{PrP}^{\mathrm{Sc}}$ level in heterozygote mice was about $65 \%$ that of their wild-type counterparts.

\section{Titration of Scrapie Infectivity in Brains of Prn-p ${ }^{0 /+}$ Mice}

Scrapie infectivity in brains of $P r n-p^{+/+}$and $P r n-p^{o /+}$ mice inoculated with mouse RML prions was determined by the incubation time assay $(28,31)$. Homogenates of brain tissue were prepared at various times after inoculation, and aliquots of each sample were injected intracerebrally into six Swiss CD-1 indicator mice. In addition, the 50-week sample was subjected to endpoint titration as described by Büeler et al. (28). Figure 4 summarizes the titers of scrapie 

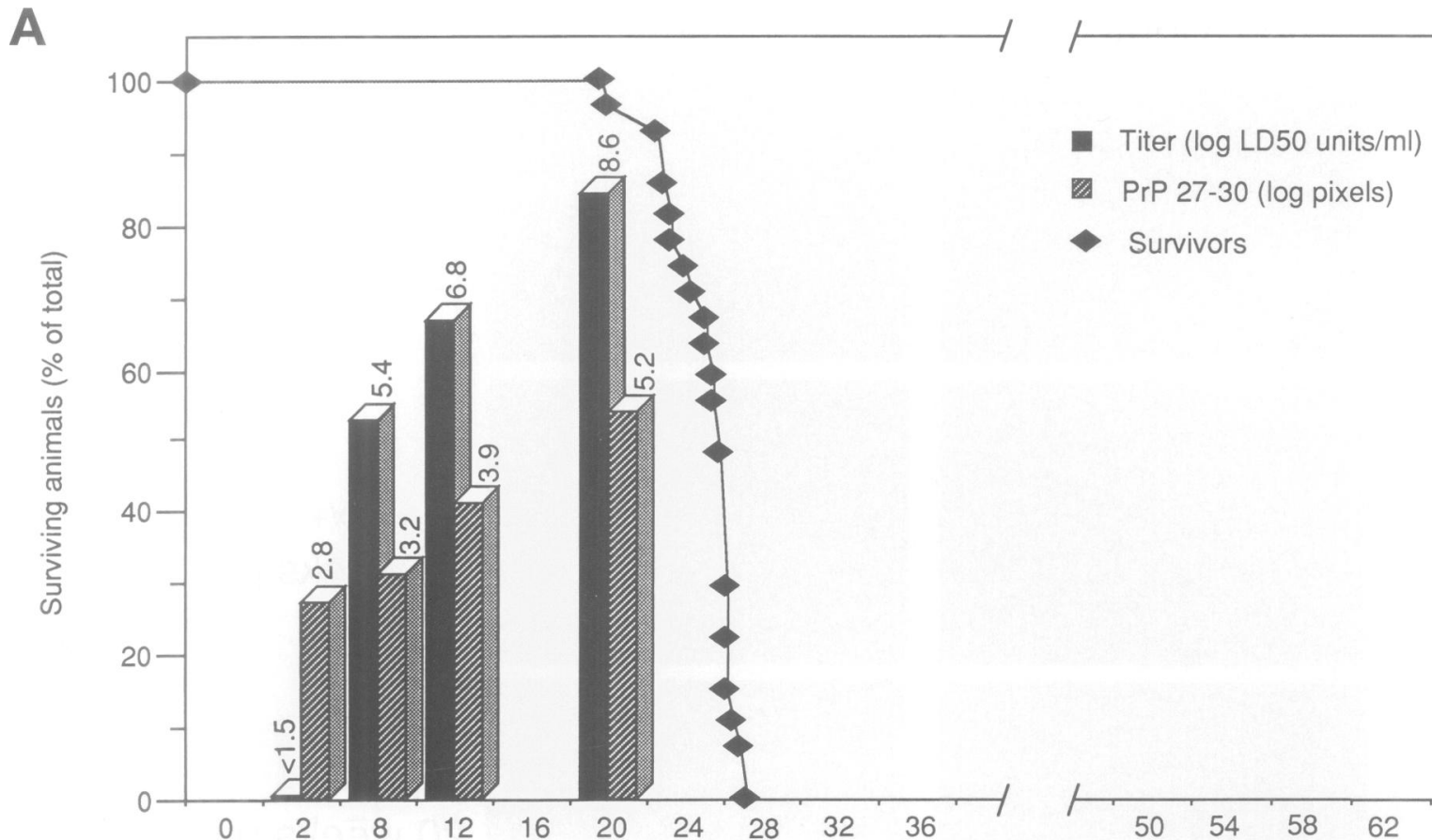

Survivors

Time (weeks after inoculation)

B
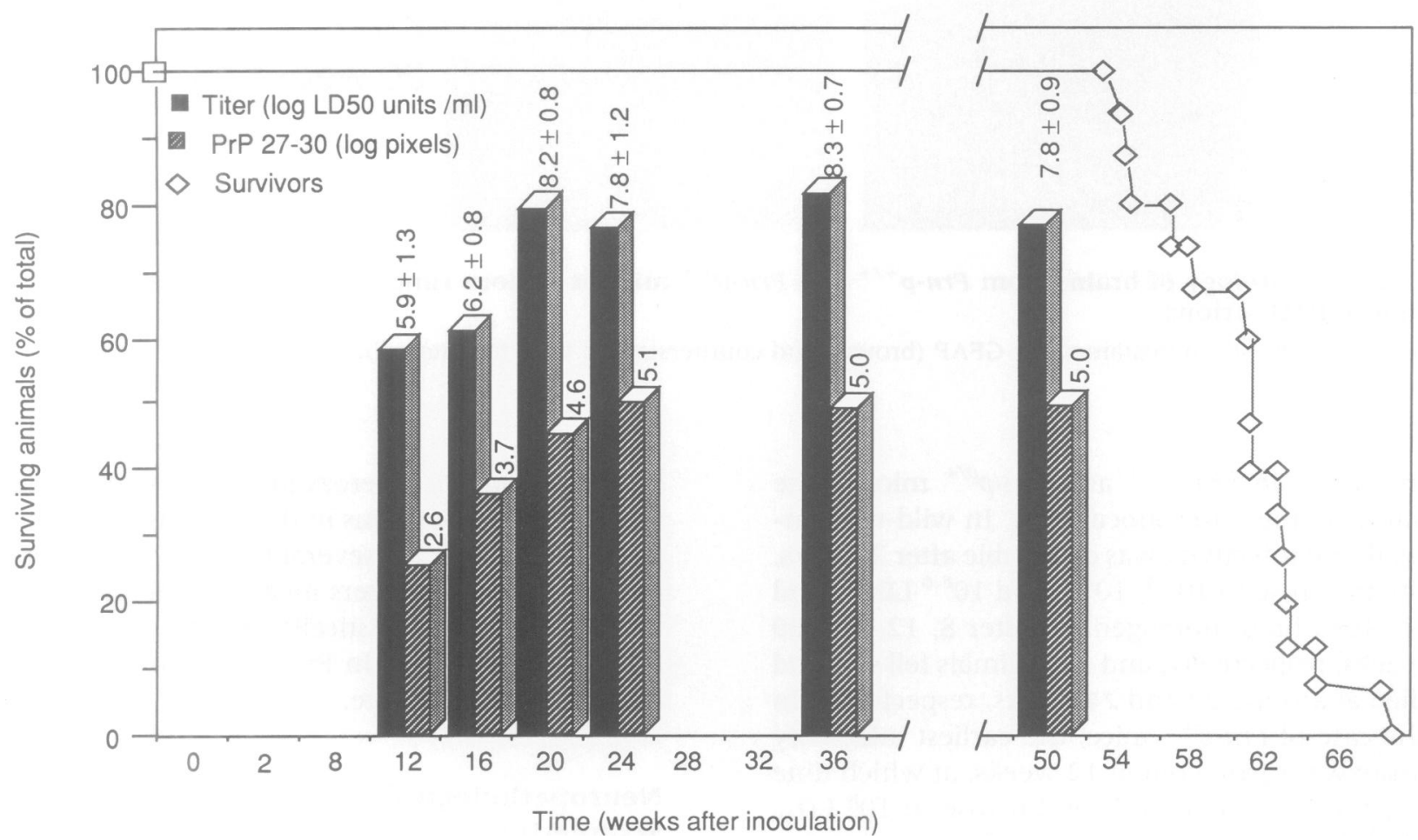

FIG. 4. Prion titers and $\operatorname{PrP}^{S c}$ in brains of mice at various times after inoculation with mouse prions Prion titers (in the $10 \%$ homogenate) and $\mathrm{PrP}^{\mathrm{Sc}}$ in brains of (A) wild-type and (B) Prn- ${ }^{0 /+}$ mice were calculated from time to death in Table 2, as described in the legend to Table 2. $\operatorname{PrP}^{\mathrm{Sc}}$ (protease-resistant $\operatorname{PrP}$ ), expressed in arbitrary units, is from Fig. 3. 
Cortex
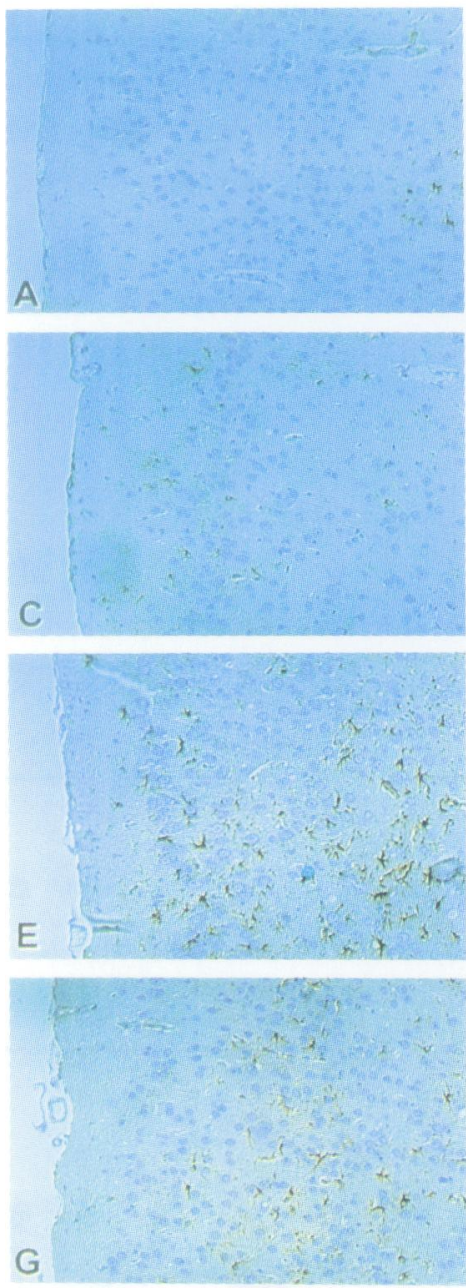

\section{Thalamus}

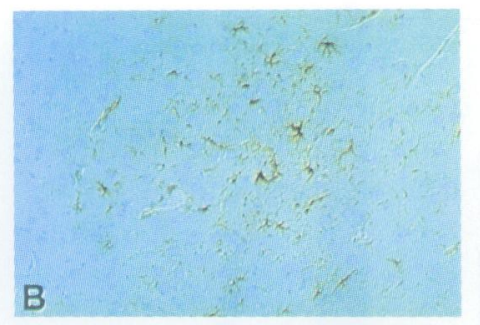

Prn- $\mathrm{p}^{+/+}$

12 weeks p.i.

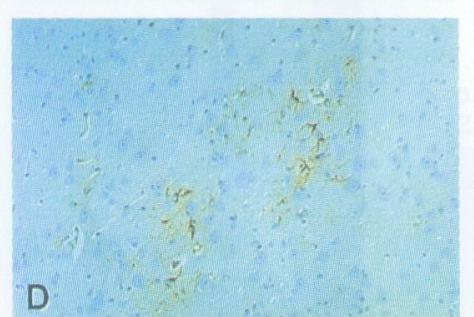

Prn- $\mathrm{p}^{\mathrm{o} /+}$

12 weeks p.i.

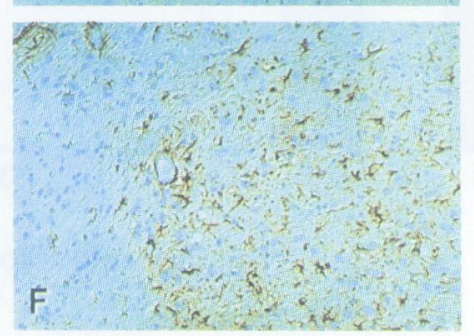

Prn- $\mathrm{p}^{+/+}$

20 weeks p.i.

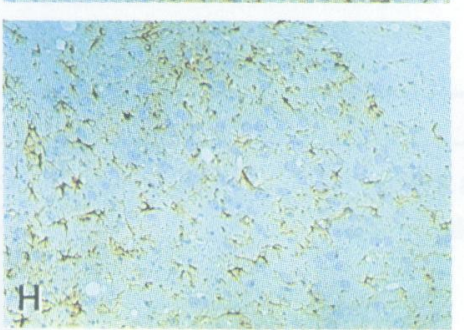

\section{Prn-po/+}

20 weeks p.i.

FIG. 5. Histology of brains from Prn- ${ }^{+/+}$and Prn-p ${ }^{o /+}$ mice at various times after inoculation with mouse RML prions

Sections were immunostained for GFAP (brown) and counterstained with hematoxylin.

infectivity in Prn- $p^{+/+}$and Prn- p $^{0 /+}$ mice at the various times after inoculation. In wild-type animals, no infectivity was detectable after 2 weeks, the titer rose to $10^{5.4}, 10^{6.8}$, and $10^{8.6} \mathrm{LD}_{50} \mathrm{U} / \mathrm{ml}$ (of $10 \%$ brain homogenate) after 8,12 , and 20 weeks, respectively, and the animals fell sick and died at around 22 and 24 weeks, respectively. In the case of Prn- $p^{0 /+}$ mice, the earliest infectivity assay was carried out at 12 weeks, at which time the titer was about $10^{6}$, and it rose to $10^{8} \mathrm{LD}_{50}$ $\mathrm{U} / \mathrm{ml}$ by 20 weeks. By 36 and 50 weeks the titer increased insignificantly to $10^{8.3} \mathrm{LD}_{50} \mathrm{U} / \mathrm{ml}$. Disease symptoms were detected at around 40 weeks, and the animals died at around 60 weeks. It is striking that wild-type animals fell sick and died within weeks of reaching a titer of about $10^{8}$
$\mathrm{LD}_{50} \mathrm{U} / \mathrm{ml}$, while heterozygous mice with about the same titers of prions in their brains remained free of symptoms for several months. The difference in the highest titers measured, about a factor of two, while statistically insignificant, could reflect the difference in $\mathrm{PrP}^{\mathrm{C}}$ levels in wild-type and heterozygous mice.

\section{Neuropathological Findings in Scrapie-Infected Prn- $\boldsymbol{p}^{0 /+}$ and Prn- $\boldsymbol{p}^{+/+}$Mice}

Prn- $p^{0 /+}$ and Prn- $p^{+/+}$mice were sacrificed at various times after inoculation, and histological sections from one sagittal half of each brain were stained with hematoxylin-eosin (data not 
TABLE 2. Scrapie infectivity and pathology in wild-type and $P r n-p^{+/ o}$ mice

\begin{tabular}{|c|c|c|c|c|}
\hline \multirow{2}{*}{$\begin{array}{l}\text { Time } \\
\text { (Weeks p.i.) }\end{array}$} & \multicolumn{2}{|c|}{ Infectivity (Days to Death) } & \multicolumn{2}{|c|}{ Pathology (G/S) } \\
\hline & Prn $-p^{+1+a}$ & Prn- $p^{+/ o}$ & Prn-p $p^{+/+}$ & Prn- $p^{+/ o}$ \\
\hline 8 & $166 \pm 5$ & ND & ND & ND \\
\hline 12 & $158 \pm 12$ & $174 \pm 13$ & $++1-$ & $++1-$ \\
\hline 16 & ND & $170 \pm 7$ & ND & $++1-$ \\
\hline 20 & $149 \pm 8$ & $148 \pm 7$ & $+++1++$ & $++1+$ \\
\hline 24 & $149 \pm 7$ & $153 \pm 13$ & $+++1++$ & $+++1+$ \\
\hline 33 & Dead & $147 \pm 5$ & Dead & $+++(\mathrm{f}) /++(\mathrm{f})$ \\
\hline 41 & & $151 \pm 9$ & & $+++/+++$ \\
\hline 45 & & $157 \pm 6$ & & $++1++$ \\
\hline 48 & & $150 \pm 9$ & & $++1++$ \\
\hline 50 & & $153 \pm 9$ & & $+++1++$ \\
\hline
\end{tabular}

Four Prn-p ${ }^{o /+}$ mice were sacrificed at 12, 16, 20, and 24 weeks after inoculation with mouse RML prions. Their brains were excised, pooled, and $1 \%(\mathrm{w} / \mathrm{v})$ homogenates were titrated by inoculation into 6 Swiss CD-1 mice (incubation time method). Individual Prn- $p^{0 /+}$ brains recovered between 33 and 50 weeks after inoculation were titrated in the same fashion. The 50-week sample was also titrated by endpoint dilution as described in Experimental Procedures. The titers in Prn- $p^{0 /+}$ brain homogenates analyzed by the incubation time method were calculated by using standard curves that describe linear relationships between survival times of $P r n-p^{+/+}$mice and infectious titers for RML prions, as described previously (28); (legend to Table 3). Titers given in the table refer to $10 \%$ homogenates. -, no gliosis or spongiosis; + , single reactive astrocytes, no spongiosis; ++ , clusters of reactive astrocytes and/or mild spongiosis; +++ , confluent foci of gliosis and/or profound spongiosis; ND, not determined; f, focal; G, gliosis; S, spongiosis.

${ }^{a}$ Data from (28) for heated samples.

shown) or with antisera to glial fibrillary acidic protein (GFAP; Fig. 5).

The characteristic hallmarks of mouse scrapie, i.e., spongiosis and astrogliosis, were obvious in sections from both Prn-p ${ }^{o /+}$ and Prn- $p^{+/+}$ mice sacrificed after the onset of clinical symptoms. A pronounced astroglial reaction, as demonstrated by enhanced GFAP immunoreactivity, preceded the appearance of spongiosis and was seen earliest and most prominently within the hippocampal formation (data not shown) as well as in the thalamus (Figs. 5B, 5D, 5F, and 5H). Astrogliosis was also evident within the cortical ribbon, where it first involved only small clusters of astrocytes predominantly in the deep cortical layers and later affected the cortex in its entire thickness (Figs. 5A, 5C, 5E, and 5G). Focal destruction of the cerebral parenchyme and severe neuronal loss, as is seen in human spongiform encephalopathies and sometimes also in scrapieinfected mice carrying multiple copies of the hamster Prn-p gene, were not observed in Prn$p^{0 /+}$ mice even at very late time points.

The extent of gliosis and status spongiosus in Prn- $p^{0 /+}$ and Prn- $p^{+/+}$mice was evaluated qual- itatively (Table 2). These parameters showed some variation between animals belonging to the same experimental group and sacrificed at the same time after infection. However, histological evaluation of groups of four mice at 12, 16, 20, and 24 weeks postinfection, respectively, suggested that Prn- $p^{0 /+}$ mice often developed pathologies similar to those of their Prn- $p^{+/+}$counterparts with a delay of approximately 4 weeks. Most interestingly, the pathological changes in $P r n-p^{0 /+}$ mice did not show significant progression at later time points.

\section{DISCUSSION}

Studies on transgenic mice carrying different copy numbers of PrP genes and expressing PrP at different levels have shown that susceptibility to clinical disease, as evidenced by incubation time and disease progression, is inversely correlated to PrP expression levels $(3,30)$. We have found that Prn- $p^{0 / 0}$ mice (32), which are devoid of PrP, are completely resistant to scrapie and that Prn- $p^{0 /+}$ mice, which contain about half the normal level 
of PrP, show very long incubation times as compared with wild-type mice ( 290 versus 158 days) and slower progression to death (125 versus 13 days) (28). Prusiner et al. (29), using the mouse strains obtained from us, found a longer incubation time in Prn- $p^{0 /+}$ mice than we had (426 days). We believe the difference is due to the criteria used for diagnosing onset of disease, which in the case of Prusiner's group are ataxia, mincing gait, "plastic tail," disorientation, feet clasping when lifted, and depression, while we applied less stringent criteria, namely diminished motor activity and disorientation. Time of death, which is less open to variable interpretation, was about the same in both studies.

In the scrapie-infected mouse, the most prominent neuropathological abnormalities are the status spongiosus, the astroglial reaction, and the loss of CNS neurons. Given the dramatic increase in the life expectancy of scrapie-inoculated $P r n-p^{0 /+}$ mice, one might have expected a marked delay and reduction in the extent of these pathological findings as compared with Prn- $p^{+/+}$mice. However, our data show that the development of gliosis and spongiosis is only marginally delayed in Prn- $p^{0 /+}$ mice and is largely dissociated from the clinical condition of the mice at later time points. These surprising findings are in agreement with the appearance of high $\operatorname{PrP}^{\mathrm{Sc}}$ and infectivity levels in clinically asymptomatic Prn- $p^{0 /+}$ mice at early time points and suggest that the development of status spongiosus and astrogliosis is not the main factor leading to clinical disease in mouse scrapie.

The finding that times to onset of disease and to death were prolonged in Prn- $p^{0 /+}$ animals was not unexpected in view of the dependency of incubation time on the PrP level, however the magnitude of the effect was surprising. We have argued (32) that the clinical symptoms of scrapie are not due to depletion of $\operatorname{PrP}^{\mathrm{C}}$ because Prn- $p^{0 / 0}$ mice show no impairment in their behavior or well-being, despite a reduction in LTP (33) and that it is more likely that accumulation of $\operatorname{PrP}^{\mathrm{Sc}}$ may cause the encephalopathy. If this were so, it could mean that there is a level of $\operatorname{PrP}^{\mathrm{Sc}}$ that neurons and/or glia can tolerate and survive and that this level is exceeded by but little in Prn- $p^{0 /+}$ animals. Perhaps animals producing only onequarter of the normal $\operatorname{PrP}^{\mathrm{C}}$ level could survive inoculation for their normal lifespan while accumulating substantial infectivity in their brains.

Our findings imply that if an organism has a low level of $\mathrm{PrP}^{\mathrm{C}}$ for either genetic or other rea- sons, it may carry a high level of infectivity without showing clinical signs of infection. It is conceivable that there is a higher level of prion carriers than would be estimated from the incidence of prion diseases such as Creutzfeld-Jakob disease. If this were so the risk of inadvertant transmission of human prion diseases by dura mater and corneal transplants could be higher than estimated (34).

\section{ACKNOWLEDGMENTS}

We thank S. Prusiner for the R073 antiserum and for the $\operatorname{tg}(\mathrm{SHaPrP}) 81$ mice and P. Autenried for providing animal facilities. This work was supported by grants from the Kanton of Zürich, the Schweizerische Nationalfonds, and $\mathrm{NIH}$ NS22786.

\section{REFERENCES}

1. Prusiner SB. (1982) Novel proteinaceous infectious particles cause scrapie. Science 216: 136-144.

2. Prusiner SB. (1989) Scrapie prions. Annu. Rev. Microbiol. 43: 345-374.

3. Prusiner SB, Scott M, Foster D, et al. (1990) Transgenetic studies implicate interactions between homologous PrP isoforms in scrapie prion replication. Cell 63: 673-686.

4. Prusiner SB. (1993) Transgenetic investigations of prion diseases of humans and animals. Philos. Trans. R. Soc. Lond. Biol. 339: 239-254.

5. Weissmann C, Büeler $\mathrm{H}$, Fischer $M$, Aguet M. (1993) Role of the PrP gene in transmissible spongiform encephalopathies. In: Zinkernagel RM, Stauffacher W (eds). Viruses and Virus-like Agents in Disease. Karger, Basel, pp. 164-175.

6. Oesch B, Westaway D, Walchli $M$, et al. (1985) A cellular gene encodes scrapie PrP 27-30 protein. Cell 40: 735-746.

7. Chesebro B, Race R, Wehrly K, et al. (1985) Identification of scrapie prion protein-specific messenger RNA in scrapie-infected and uninfected brain. Nature 315: 331-333.

8. Basler K, Oesch B, Scott M, et al. (1986) Scrapie and cellular PrP isoforms are encoded by the same chromosomal gene. Cell 46: 417-428.

9. Stahl N, Borchelt DR, Hsiao K, Prusiner SB. (1987) Scrapie prion protein contains a 
phosphatidylinositol glycolipid. Cell 51: 229240.

10. Stahl N, Baldwin MA, Hecker R, Pan KM, Burlingame AL, Prusiner SB. (1993) Glycosylinositol phospholipid anchors of the scrapie and cellular prion proteins contain sialic acid. Biochemistry 31: 5043-5053.

11. Manson J, West JD, Thomson V, Mcbride P, Kaufman MH, Hope J. (1992) The prion protein gene: A role in mouse embryogenesis? Dev. Camb. 115: 117-122.

12. Bendheim PE, Brown HR, Rudelli RD, et al. (1992) Nearly ubiquitous tissue distribution of the scrapie agent precursor protein. $\mathrm{Neu}$ rology 42: 149-156.

13. Scott M, Foster D, Mirenda C, et al. (1989) Transgenic mice expressing hamster prion protein produce species-specific scrapie infectivity and amyloid plaques. Cell 59: 847857.

14. McKinley MP, Taraboulos A, Kenaga L, et al. (1991) Ultrastructural localization of scrapie prion proteins in cytoplasmic vesicles of infected cultured cells. Lab. Invest. 65: 622630.

15. Taraboulos A, Rogers $M$, Borchelt DR, et al. (1990) Acquisition of protease resistance by prion proteins in scrapie-infected cells does not require asparagine-linked glycosylation. Proc. Natl. Acad. Sci. U.S.A. 87: 8262-8266.

16. Taraboulos A, Serban D, Prusiner SB. (1990) Scrapie prion proteins accumulate in the cytoplasm of persistently infected cultured cells. J. Cell Biol. 110: 2117-2132.

17. Turk E, Teplow DB, Hood LE, Prusiner SB. (1988) Purification and properties of the cellular and scrapie hamster prion proteins. Eur. J. Biochem. 176: 21-30.

18. Stahl N, Baldwin MA, Teplow DB, et al. (1993) Structural studies of the scrapie prion protein using mass spectrometry and amino acid sequencing. Biochemistry 32: 1991-2002.

19. Bolton DC, Bendheim PE. (1988) A modified host protein model of scrapie. In: Bock G, Marsh J (eds). Novel Infectious Agents and the Central Nervous System. John Wiley \& Sons, Chichester, U.K., pp. 164-177.

20. Prusiner SB. (1991) Molecular biology of prion diseases. Science 252: 1515-1522.

21. Oesch B, Groth DF, Prusiner SB, Weissmann C. (1988) Search for a scrapie-specific nucleic acid: A progress report. In: Bock G, Marsh J (eds). Novel Infectious Agents and the Central Nervous System. John Wiley \& Sons, Chichester, U.K. pp. 209-223.
22. Pan KM, Baldwin M, Nguyen J, et al. (1993) Conversion of alpha-helices into beta-sheets features in the formation of the scrapie prion proteins. Proc. Natl. Acad. Sci. U.S.A. 90: 10962-10966.

23. Dickinson AG, Outram GW. (1988) Genetic aspects of unconventional virus infections: The basis of the virino hypothesis. Ciba Found. Symp. 135: 63-83.

24. Bruce ME, Dickinson AG. (1987) Biological evidence that scrapie agent has an independent genome. J. Gen. Virol. 68: 79-89.

25. Weissmann C, Büeler H, Sailer A, Fischer M, Aguet M, Aguzzi A. (1993) Role of PrP in prion diseases. Brit. Med. Bull. 49: 995-1011.

26. Prusiner SB. (1992) Molecular biology and genetics of neurodegenerative diseases caused by prions. Adv. Virus Res. 41: 241280.

27. Sailer A, Büeler $H$, Fischer $M$, Aguzzi A, Weissmann C. (1994) No propagation of prions in mice devoid of PrP. Cell 77: 967-968.

28. Büeler H, Aguzzi A, Sailer A, et al. (1993) Mice devoid of PrP are resistant to scrapie. Cell 73: 1339-1347.

29. Prusiner SB, Groth D, Serban A, et al. (1993) Ablation of the prion protein (PrP) gene in mice prevents scrapie and facilitates production of anti-PrP antibodies. Proc. Natl. Acad. Sci. U.S.A. 90: 10608-10612.

30. Carlson GA, Ebeling C, Yang S-L, et al. (1994) Prion isolate specified allotypic interactions between the cellular and scrapie prion proteins in congenic and transgenic mice. Proc. Natl. Acad. Sci. U.S.A. 91: 56905694.

31. Prusiner SB, Cochran SP, Groth DF, Downey DE, Bowman KA, Martinez HM. (1982) Measurement of the scrapie agent using an incubation time interval assay. Ann. Neurol. 11: 353-358.

32. Büeler H, Fischer M, Lang $Y$, et al. (1992) Normal development and behaviour of mice lacking the neuronal cell-surface PrP protein. Nature 356: 577-582.

33. Collinge J, Whittington MA, Sidle KCL, et al. (1994) Prion protein is necessary for normal synaptic function. Nature 370: 295-297.

34. Brown P, Kaur P, Sulima MP, Goldfarb LG, Gibbs CJ, Gajdusek D. (1993) Real and imagined clinicopathological limits of "prion dementia." Lancet 341: 127-129.

35. Chandler RL. (1961) Encephalopathy in mice produced by inoculation with scrapie brain material. Lancet 1: 1378-1379. 
36. Brown P, Wolff A, Gajdusek DC. (1990) A simple and effective method for inactivating virus infectivity in formalin-fixed tissue samples from patients with Creutzfeldt-Jakob disease. Neurology 40: 887-890.

37. Lämmli UK. (1970) Cleavage of structural proteins during the assembly of the head of bacteriophage T4. Nature 227: 680-685.

38. Serban D, Taraboulos A, DeArmond SJ, Prusiner SB. (1990) Rapid detection of Creutzfeldt-Jakob disease and scrapie prion proteins. Neurology 40: 110-117. 